SHORT REPORT

\title{
The effect of fatigue on abnormal vibration induced illusion of movement in idiopathic focal dystonia
}

\author{
N Frima, S M Rome, R A Grünewald
}

J Neurol Neurosurg Psychiatry 2003;74:1 154-1156

Background: Perception of vibration induced illusionary movement (VIIM) is subnormal in dystonic patients, suggesting abnormal sensory-motor processing in patients with idiopathic focal dystonia.

Objective: To examine the effects of fatigue on VIIM in patients with idiopathic torticollis.

Methods: An illusionary sensation of arm extension was evoked by an $80 \mathrm{~Hz}$ transcutaneous vibratory stimulus applied to the biceps brachii tendon while the arm was restrained. Blindfolded patients attempted to copy the perceived movement of the vibrated arm with the opposite (tracking) arm and the change in elbow angle of the tracking arm was quantified over 45 seconds. The tasks were repeated following volitional fatigue of the vibrated arm. Results: The subnormal perception of VIIM perceived by patients with torticollis, occurring bilaterally and remote from the location of dystonic symptoms, was corrected by fatigue of the vibrated arm compared with prefatigue values (mean (SEM): $19.04^{\circ}(1.76)^{\circ} \vee 24.25^{\circ}\left(2.41^{\circ}\right)$; $\mathrm{p}=0.01$, paired $t$ test).

Conclusions: While a combination of central or peripheral factors may be involved in the correction of abnormal perception of the vibration induced illusion of movement in dystonia, subnormal elasticity of muscle spindles could be implicated in the impaired perception of vibration induced illusionary movement and may predispose an individual towards developing idiopathic focal dystonia.

M uscle spindles, innervated by Ia and II afferents and $\gamma$ efferent fibres, provide information on muscle stretch and velocity and contribute to the sense of limb movement and position. ${ }^{1}$ Such afferent activity comprises part of the sensory feedback required for motor learning.

Transcutaneous vibration of muscle tendon or belly at 50-120 Hz stimulates muscle spindle primary endings, thereby inducing the tonic vibration reflex. ${ }^{1}$ The long latency, slow developing tension, and sensitivity to anaesthesia suggest that polysynaptic pathways, including descending cortical influences, have a part to play in the evocation of muscle contraction by vibration. ${ }^{2-4}$ Vibration of a muscle while it is immobilised elicits an illusionary sensation of movement whereby the muscle undergoing vibration is perceived to be stretching $^{1}$ (vibration induced illusion of movement, VIIM); in the case of the biceps muscle the elbow is perceived to be extending.

Microneurographic recordings have shown that the origin of the vibration induced illusionary sensation of movement lies in the Ia afferent fibres. ${ }^{5}$ Immobilisation of the arm minimises afferent input from the joint capsule. When the arm is relaxed, group Ib and group II afferent and $\gamma$ efferent activity are also minimised. ${ }^{16}$ Activity from cutaneous afferents contributes minimally to the illusion of movement in such circumstances, and abnormal perception of activity of none of these receptors is likely to influence VIIM in the relaxed, immobilised arm.

We have previously demonstrated that despite an apparently normal tonic vibration reflex, perception of vibration induced arm movement is impaired in patients with idiopathic focal dystonia. ${ }^{7}$ In addition, perception of VIIM is subnormal in dystonic patients compared with healthy volunteers and patients with idiopathic Parkinson's disease. ${ }^{8}$ Therefore, these findings implicate widespread abnormal processing of Ia afferent activity in the pathophysiology of idiopathic dystonia. Because of the role of repetitive movements in triggering some forms of focal dystonia (for example, writer's cramp and musician's cramp), we examined the effects of fatigue on VIIM in dystonic patients.

\section{METHODS}

Written consent was obtained from all participants and the South Sheffield research ethics committee approved the experimental protocol.

\section{Participants}

Patients with idiopathic dystonia were recruited from the movement disorder clinic at the Royal Hallamshire Hospital in Sheffield, UK. Healthy controls were recruited from volunteers and spouses of dystonic patients. No patient or control subject had psychiatric or other neurological impairment. All patients had idiopathic torticollis, and one patient also had axial dystonia (table 1).

Twenty one patients with torticollis were studied - 15 with head rotation to the right and six to the left. Eight were receiving botulinum toxin injections every three to six months, divided between the sternocleidomastoid and posterior cervical muscles, and 14 had been tested previously. Twenty patients were self declared right handed and one left handed.

Eighteen healthy controls were recruited. Fifteen were self declared right handed and three left handed. Twelve had been tested previously. None had diabetes or a family history of dystonia.

\section{Experimental design}

The perception of VIIM evoked by vibration of an immobilised arm was tested as reported elsewhere ${ }^{8}$; modifications of the technique are described briefly here.

The blindfolded individuals sat comfortably at a table with one arm placed in a custom made polypropylene splint, with the elbow flexed to approximately $100^{\circ}$ (vibrated arm). The volunteers were instructed to flex the opposite (tracking arm) until they felt both arms were parallel. The participants were asked to relax their arms, while maintaining arm position, and

Abbreviations: VIIM, vibration induced illusion of movement 
Table 1 Characteristics of healthy control subjects and dystonic subjects participating in the study

\begin{tabular}{llll}
\hline Subjects & Sex (M/F) & Age (years) (range) & $\begin{array}{l}\text { Duration of symptoms (years) } \\
\text { (range) }\end{array}$ \\
\hline $\begin{array}{l}\text { Controls }(n=18) \\
\begin{array}{c}\text { Patients }(n=21): \\
\text { torticollis to right } \\
\text { torticollis to left }\end{array}\end{array}$ & $6 / 12$ & $59(30$ to 75$)$ & - \\
\hline
\end{tabular}

relaxation of the vibrated arm was confirmed by surface EMG recordings. Electrical silence of the surface EMG was obtained before starting the vibratory stimulus. An $80 \mathrm{~Hz}$ frequency, 0.5 mm amplitude vibration was applied transcutaneously to the biceps brachii tendon just above the elbow joint for 45 seconds, using a battery operated vibrator (FertiCare personal, Multicept A/S, Horsholm, Denmark). The volunteers were asked to copy accurately the sensation of movement they perceived in the vibrated arm with the tracking arm.

Participants' strength was estimated using a dynamometer and dumb-bell weight ( $1-5 \mathrm{~kg}$ ) selected depending on their strength, to ensure gradual fatigue of the participants' muscles. Volunteers then performed repeated biceps curls until they felt they could no longer raise the dumb-bell. The test was repeated twice in each arm. As the biceps muscle recovered strength, participants were instructed to raise the weight again in between the tasks to maintain fatigue. The arm that was vibrated first was selected randomly.

The change of elbow angle in the tracking arm as a result of the VIIM in the vibrated arm was recorded using a digital camera and measured on the digital images using Adobe PhotoShop software. The perception of illusionary movement was measured as angular displacement of the tracking arm from initial to final position during the 45 second test period.

\section{Statistical analysis}

Paired and unpaired $t$ tests were used, where appropriate. Statistical significance was determined as $p<0.05$. Values are shown as mean (SEM).

\section{RESULTS}

The mean initial elbow angle of the tracking arm was 35.10 $\left(1.22^{\circ}\right)$ for dystonic patients and $37.07^{\circ}\left(1.56^{\circ}\right)$ for control volunteers. There was no difference in initial elbow angle between dystonic patients and healthy control volunteers before or after fatigue (controls: $37.70^{\circ}\left(1.27^{\circ}\right)$; dystonic patients: $34.34^{\circ}\left(1.16^{\circ}\right) ; \mathrm{p}>0.05$, unpaired and paired $t$ tests $)$.

Vibration of the biceps brachii tendon induced a perception of illusionary movement bilaterally in all healthy control volunteers, which they tracked with the opposite arm. At the end of the test, extension of the tracking arm was less in dystonic patients than in the healthy volunteers, at $19.04^{\circ}\left(1.76^{\circ}\right) \mathrm{v}$ $28.56^{\circ}\left(1.66^{\circ}\right), \mathrm{p}<0.01$ (unpaired $t$ test).

After fatigue, the illusion of movement perceived by dystonic patients increased (to $24.25^{\circ}\left(2.42^{\circ}\right.$ )) so that it did not differ from that of healthy control volunteers $\left(26.91^{\circ}\right.$ $\left(2.20^{\circ}\right)$; $\mathrm{p}>0.05$, unpaired $t$ test). The perception of movement after fatigue of the vibrated arm increased significantly in dystonic patients compared with their perception before fatigue ( $p=0.01$, paired $t$ test). This was not observed in healthy controls, who showed no significant effect of fatigue on the perception of illusionary arm movement.

\section{DISCUSSION}

We previously described accurate position sense but impaired perception of the tonic vibration reflex on vibration of the unrestrained biceps brachii tendon in patients with idiopathic focal dystonia. ${ }^{7}$ In a subsequent study, ${ }^{8}$ we reported subnormal VIIM that occurs when the vibrated arm is relaxed and immobilised, implicating abnormal Ia muscle spindle sensorymotor processing in the pathophysiology of dystonia. This is likely to occur as a result of the brain's attempt to interpret Ia afferent activity in the absence of fusimotor drive to the muscle spindle. ${ }^{56}$

Two possibilities may explain the increased sensation of illusionary movement following fatigue in dystonic participants: subnormal muscle spindle responsiveness to stretch improving with fatigue of the muscle, or subnormal responsiveness of the central nervous system to normal Ia afferent input improving when the muscle is fatigued.

The abnormality of perception of VIIM is found in the relaxed, immobilised biceps, and is corrected by fatigue even when the fatigued vibrated muscle remains relaxed. As $\gamma$ efferent activity is minimal in the relaxed state, ${ }^{6}$ it is unlikely that the change in perception of the stimulus after fatigue can be attributed to a change in the $\gamma$ loop gain. One possible explanation for these observations is an underlying abnormality of muscle spindle elasticity. Explanations of these results based on central mechanisms may also be plausible-for instance, a differential response of the $\gamma$ loop to fatigue in dystonic and non-dystonic participants, alterations in premotor cortical activity as a result of fatigue, or spinal modulation of peripheral input.

Abnormalities observed in dystonic patients during stretch reflexes ${ }^{910}$ and during the vibration induced sensation of arm movement ${ }^{78}$ suggest reduced sensitivity to vibration and delayed cessation of activity of the muscle spindle, so that activation of Ia afferent fibres continues for a prolonged period after cessation of stretch. ${ }^{10}$ Our results show that impaired sensitivity to muscle stretch occurs bilaterally and remote from the location of dystonic symptoms.

A conditioning contraction of skeletal muscle increases muscle spindle sensitivity to subsequent muscle stretch. ${ }^{11}$ In dystonic patients, we propose that, after stretching as the muscle fatigues, relatively inelastic nuclear bag fibres in dystonic muscle can alter their response characteristics more markedly than in normal individuals, and for a prolonged period increase their sensitivity to vibration. Although gross muscle spindle histology appears normal in dystonia, ${ }^{12}$ this does not exclude a subtle abnormality of elasticity that may be genetically determined. ${ }^{13}$

We speculate that it is the adaptation of the brain to the change in Ia afferent response in fatigued muscle that triggers dystonic symptoms. Abnormalities of motor programmes in dystonia have been reported previously elsewhere. ${ }^{14-16}$ Development of dystonic symptoms would depend on "training" a motor programme in the fatigued state, which may then "corrupt" and remain fixed regardless of the state of fatigue of the muscle. The motor programme output for the dystonic muscle would then be appropriate for the fatigued state but excessive in the non-fatigued state. This would account for the brief improvement in symptoms in occupational dystonia after fatigue of the affected part. ${ }^{17}$ This mechanism would explain the development of dystonia after overuse of a muscle group or the prolonged maintenance of an abnormal posture, such as occurs in writer's cramp or musician's cramp. 


\section{ACKNOWLEDGEMENTS}

We thank the Dystonia Society and the Ballroom Dancers of Doncaster for funding the study and the participants for taking part.

\section{Authors' affiliations}

N Frima, S M Rome, R A Grünewald, Academic Neurology Unit, Division of Genomic Medicine, University of Sheffield, Royal Hallamshire Hospital, Sheffield, UK

\section{Competing interests: none declared}

Correspondence to: Dr Richard A Grünewald, Section of Clinical Neurology, N Floor, Royal Hallamshire Hospital, Glossop Road, Sheffield S10 2JF, UK; r.a.grunewald@sheffield.ac.uk

Received 25 July 2002

In revised form 13 November 2002

Accepted 14 November 2002

\section{REFERENCES}

1 Goodwin GM, McCloskey DI, Matthews PB. The contribution of muscle afferents to kinaesthesia shown by vibration induced illusions of movement and by the effects of paralysing joint afferents. Brain 1972:95:705-48.

2 De Gail P, Lance JW, Neilson PD. Differential effects on tonic and phasic reflex mechanisms produced by vibration of muscles in man. $J$ Neurol Neurosurg Psychiatry 1966;29:1-11.

3 Gillies JD, Burke DJ, Lance JW. The supraspinal control of the tonic vibration reflex. Proc Aust Assoc Neurol 1971;8:143-6.

4 Kanda K. Contribution of polysynaptic pathways to the tonic vibration reflex. Jpn J Physiol 1972;22:367-77.
5 Roll JP, Vedel JP. Kinaesthetic role of muscle afferents in man, studied by tendon vibration and microneurography. Exp Brain Res 1982;47:177-90

6 Burke D, Hagbarth KE, Lofstedt L, et al. The responses of human muscle spindle endings to vibration of non-contracting muscle. J Physiol (Lond) 1976:261:673-93.

7 Grünewald RA, Yoneda Y, Shipman JM, et al. Idiopathic focal dystonia: a disorder of muscle spindle afferent processing? Brain 1997; 120:2179-85.

8 Rome S, Grünewald RA. Abnormal perception of the vibration-induced illusion of movement in dystonia. Neurology 1999:53:1794-800.

9 Rothwell JC. The pathophysiology of dystonias. Adv Neurol 1983;39:851-63.

10 Tatton WG, Bedingham MC, Verrier MC, et al. Characteristic alterations in responses to imposed wrist displacements in Parkinsonian rigidity and dystonia musculorum deformans. Can J Neurol Sci 1984;11:281-7.

11 Gandevia SC. Neural control in human muscle fatigue: changes in muscle afferents, motor neurones and motor cortical drive. Acta Physiol Scand 1998; 162:275-83

12 Swash M, Fox KP. Normal muscle spindles in idiopathic torsion dystonia. J Neurol Sci 1976;27:525-7.

13 Rome S, Grünewald RA. Perception of vibration-induced illusionary movement in first-degree relatives of patients with dystonia [abstract] Mov Disord 2000;15(suppl 3): 140

14 Gelb DJ, Yoshimura DM, Olney RK, et al. Change in pattern of muscle activity following botulinum toxin injections for torticollis. Ann Neurol 1991;29:370-6.

15 Kaji R, lkeda A, lkeda T, et al. Physiological study of cervical dystonia: task-specific abnormality in contingent negative variation. Brain $1995 ; 118: 511-22$

16 Deuschl G, Heinen F, Kleedorfer B, et al. Clinical and polymyographic investigation of spasmodic torticollis. J Neurol 1992;239:9-15.

17 Pesenti A, Priori A, Scarlato G, et al. Transient improvement induced by motor fatigue in focal occupational dystonia: the handgrip test. Mov Disord 2001;16:1143-7.

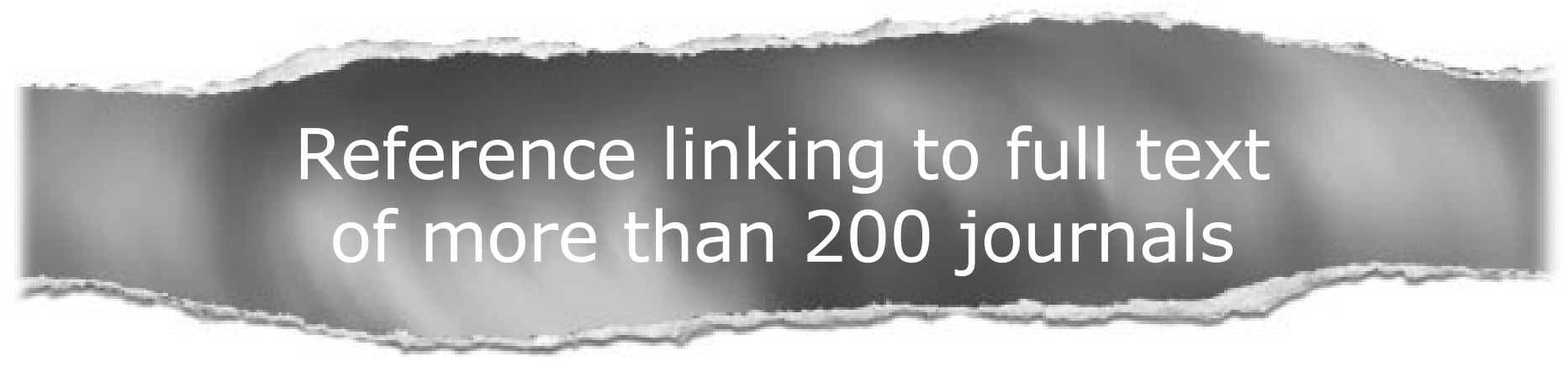

\section{Toll free links}

You can access the FULL TEXT of articles cited in the Journal of Neurology, Neurosurgery, and Psychiatry online if the citation is to one of the more than 200 journals hosted by HighWire (http://highwire.stanford.edu) without a subscription to that journal. There are also direct links from references to the Medline abstract for other titles.

\section{www.jnnp.com}

